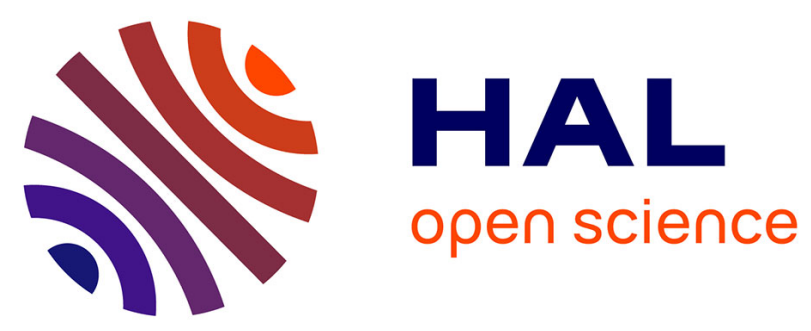

\title{
Development of an electron paramagnetic resonance methodology for studying the photo-generation of reactive species in semiconductor nano-particle assembled films
}

Marek Twardoch, Youcef Messai, Bertrand Vileno, Yannick Hoarau, Djamel E

Mekki, Olivier Felix, Philippe Turek, Jean Weiss, Gero Decher, David Martel

\section{To cite this version:}

Marek Twardoch, Youcef Messai, Bertrand Vileno, Yannick Hoarau, Djamel E Mekki, et al.. Development of an electron paramagnetic resonance methodology for studying the photo-generation of reactive species in semiconductor nano-particle assembled films. Molecular Physics, 2018, 116 (12), pp.1558-1564. 10.1080/00268976.2018.1433882 . hal-03522607

\section{HAL Id: hal-03522607 https://hal.science/hal-03522607}

Submitted on 12 Jan 2022

HAL is a multi-disciplinary open access archive for the deposit and dissemination of scientific research documents, whether they are published or not. The documents may come from teaching and research institutions in France or abroad, or from public or private research centers.
L'archive ouverte pluridisciplinaire HAL, est destinée au dépôt et à la diffusion de documents scientifiques de niveau recherche, publiés ou non, émanant des établissements d'enseignement et de recherche français ou étrangers, des laboratoires publics ou privés. 


\title{
Development of an electron paramagnetic resonance methodology for studying the photo-generation of reactive species in semiconductor nano- particle assembled films
}

\author{
Marek Twardoch ${ }^{a}$, Youcef Messai ${ }^{b, c}$, Bertrand Vileno ${ }^{b, d}$, Yannick Hoarau ${ }^{e}$, Djamel E. Mekki ${ }^{c}$, Olivier \\ Felix $^{\mathrm{a}}$, Philippe Turek ${ }^{\mathrm{b}, \mathrm{d}}$, Jean Weiss ${ }^{\mathrm{b}}$, Gero Decher ${ }^{\mathrm{a}, \mathrm{f}}$ and David Martel ${ }^{\mathrm{a}}$
}

anstitut Charles Sadron, Universite de Strasbourg, CNRS, Strasbourg, France.

bInstitut de Chimie, UMR 7177, Universite de Strasbourg, CNRS, Strasbourg, France.

'Laboratoire d'Etude Des Surfaces et Interfaces de La Matiere Solide (LESIMS), Universite Badji Mokhtar, Annaba, Algeria.

${ }^{\mathrm{d}}$ French EPR Federation of Research (REseau NAtional de RPE interDisciplinaire (RENARD), Federation IR-RPE CNRS \#[?]?]? Lille, France.

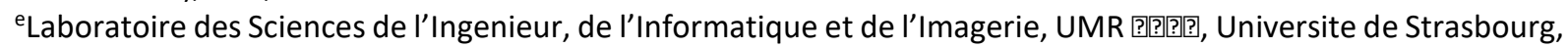
CNRS, Strasbourg, France.

fInternational Center for Frontier Research in Chemistry, Strasbourg, France.

Keywords: Thin film; semiconductor, nano-particle; EPR; kinetic of photo-generated species; modelling

\begin{abstract}
:
An experimental approach involving electron paramagnetic resonance is proposed for studying photogenerated reactive species in semiconductor nano-particle-based films deposited on the internal wall of glass capillaries. This methodology is applied here to nano-TiO2 and allows a semiquantitative analysis of the kinetic evolutions of radical production using a spin scavenger probe.
\end{abstract}

\section{Introduction:}

At the nano-scale, properties often differ from those of the bulk state enhancing the capabilities and/or leading to peculiar properties. The field of materials for photo-conversion is in line with trend in the present energy-saving strategies ${ }^{1-4}$ but requires more fundamental investigations ${ }^{5}$. As materials properties often arise from the organisation and properties of its constituents, the ability to probe andmodel the various properties of these nano-objects remain challenging. Electrical conductivity ${ }^{6}$, electronic conduction ${ }^{7}$ or optical properties ${ }^{8,9}$ are controlled by various parameters such as their size ${ }^{10}$, interface ${ }^{11}$, morphology ${ }^{12}$, and state (suspension ${ }^{13-15}, 2 \mathrm{D}$ films ${ }^{12,16}$ ) that need to be understood for future devices optimisation. Nonetheless, the investigation of nano-object properties requires the use of appropriated characterisation

techniques to get comparable measurements when performed in similar conditions. Unfortunately, a given approach only probes specific properties as for example: interfacial charge transfer ${ }^{17}$, charge carrier lifetime ${ }^{14,18}$, or photoluminescence ${ }^{19}$. Yet, the only way to get a synthetic overviewconsists in comprehensively integrating the fully acquired dataset to enhance the overall understanding. To that extend, we propose an innovative approach combining the deposition of nano-structured films on the internal wall of glass capillaries with the electronic paramagnetic resonance (EPR) spectroscopy. The aim is to probe the photo-generation of reactive species through EPR within aqueous samples. EPR is a powerful technique for probing the photo-induced radical species of semiconducting materials. In the solid state, several approaches are available: low temperature ${ }^{20}$ and room temperature using dry powder ${ }^{21}$ or suspensions ${ }^{22}$. In this later case, generated species even being paramagnetic are often too short-lived to be detected as is by EPR at room temperature. Therefore, an indirect methodology called spin-trapping ${ }^{23}$ or spin scavenging ${ }^{13}$ is used where radical-addition reaction is probed to investigate 
short-lived radicals. EPR room temperature investigations are often complicated by the presence of water (due to its high dielectric constant). Therefore, thin flat cells or sub-millimetre capillaries are required to perform EPR measurements. In this work, thanks to electrostatic interaction as driving forces, controlled hybrid coatings composed of polyelectrolyte and $\mathrm{TiO} 2$ nano-particles (nano- $\left.\mathrm{TiO}_{2}\right)^{24,25}$ were achieved on the inner walls of capillaries by stepwise formation ${ }^{26}$, also referred as layer-by-layer approach ${ }^{27,28}$. This method is an established tool for preparing nano-particle-containing films in which the nano-particle deposit architecture can be well controlled. This approach presents several benefits regarding the reproducibility, quantification and relative ease of implementation in the case of hardly accessible surfaces. It allows monitoring the film thickness from few nanometres to several hundred of nanometres and consequently the amount of the deposited material. Then, the experimental results have been confronted to simple models, which pointed out that complex mechanisms will have to be considered in the future to explain the observed behaviour.

\section{Experimental procedure:}

\section{Materials}

- TiO2 (P25-Degussa) was obtained from Evonik (Germany). Tetrabutylammoniun hydroxide (TBAOH, 55 wt.\% in water) was purchased from Sachem (USA). Sodium hydroxide ( $\mathrm{NaOH})$, polyethylenimine (PEI, $M W \approx 75,000,50 \%$ in water), polydiallyldimethylammonium chloride (PDDA, $M W \approx 100,000-$ 200,000, 20\% in water) and 4-hydroxy-2,2,6,6-tetramethylpiperidine 1-oxyl (TEMPOL 97\%) were purchased from Aldrich (France). All the compounds were used as received. Ethanol absolute anhydrous was purchased from Carlo Erba (France). Ultrapure water $(\rho=18.2 \mathrm{M} . \mathrm{cm})$ was produced with a Milli-QR ${ }^{\circledR}$ Avantage $A 10$ water purification system (Millipore, France). Glass capillaries (rincaps $50 \mu \mathrm{L}$ ) were purchased from Hirschmann (Germany). Glass plates $(32 \times 12 \times 1 \mathrm{~mm})$ were purchased from Thuet B (France).

\section{Apparatus}

- Continuous-wave EPR X-band spectrometer (EMXplus from Bruker Biospin GmbH, Germany) was equipped with a high-sensitivity resonator (4119HS-W1, Bruker). This setup was used to record the conventional fieldswept spectra from aqueous solutions containing photosensitizing solution and TEMPOL molecules. EPR measurements were performed in short intervals between the subsequent irradiation periods of $30 \mathrm{~s}$. The principal experimental parameters values were: a modulation amplitude of $0.5 \mathrm{G}$, a microwave power of $1.8 \mathrm{~mW}$, a time constant of ca. $20 \mathrm{~ms}$, and $50 \mathrm{~ms}$ conversion time and $120 \mathrm{G}$ were swept in $60 \mathrm{~s}$ per scan and one scan was recorded after each illumination step. Illumination of the capillaries was performed outside the cavity with a UV neon source: $\lambda \max =365$ $\mathrm{nm}$, i.e. $h v=3.4 \mathrm{eV}$ and $E=1.5 \mathrm{mWcm}-2$ (measured with a powermeter 1936-C from Newport). The emission spectra of the lamp and a schematic description of the experimental setup are presented in Figure S1 (Online Supplementary material). As TEMPOL does not absorb at this wavelength, there is no absorption variation during measurement. Electronic photo-generation processes occur only during the irradiation procedure and are assumed to stop as soon as the light is off illumination. All experiments were performed at room temperature ( $295 \pm 1 \mathrm{~K})$.

- UV-Vis measurements were performed with a Cary series UV-Vis-NIR 5000 spectrophotometer.

- Dynamic light scattering (DLS) measurements were performed with a Malvern zetasizer nano ZS and a folded capillary cell.

- Transmission electronic microscopy (TEM) measurements were performed with a Philips CM 12 (120 $\mathrm{kV}$ in bright field mode).

- Scanning electronic microscopy (SEM) measurements were performed with a SEM Hitachi SU8010 operated at acceleration voltage of $2 \mathrm{kV}$. For the preparation of $\mathrm{TiO}_{2}$ suspensions, a high-intensity ultrasonic processor (SONICS VCX 750) and a tapered microtip 1/8" were used. Centrifugation was performed with a Sigma 204 (Bioblock). 


\section{Suspension and solution preparation}

$\mathrm{TiO}_{2}$ suspension: $\mathrm{TiO} 2$ nano-particles display acid/base properties via the surface groups $\mathrm{Ti}-\mathrm{OH}$. In the case of $\mathrm{P} 25$, the two equilibriums, $\mathrm{Ti}-\mathrm{OH}_{2}^{+} / \mathrm{Ti}-\mathrm{OH}$ and $\mathrm{Ti}-\mathrm{OH} / \mathrm{Ti}-\mathrm{O}^{-}$, have $\mathrm{pKa}$ values around 5 and $8{ }^{29}$, respectively. In this study, the $\mathrm{pH}$ for the preparation of films was 10-10.5 to develop a negative charge of the $\mathrm{TiO}_{2}$ nano-particles. First, the $\mathrm{pH}$ of $40 \mathrm{~mL}$ of water was adjusted at 10.5-11 with TBAOH and transferred in a cylindrical Teflon container prior to the addition of $1 \mathrm{~g}$ of $\mathrm{TiO}_{2}\left(25 \mathrm{~g} \mathrm{~L}^{-1}\right)$. Then, the suspension was stirred for $1 \mathrm{~h}(600 \mathrm{rpm})$ and sonicated for $25 \mathrm{~min}(600 \mathrm{~kJ}, 40 \%)$. After reaching room temperature, the $\mathrm{pH}$ was adjusted to 10-10.5 with TBAOH. The suspension was centrifuged

for $15 \mathrm{~min}$ at $4000 \mathrm{rpm}$. PEI solution: $1 \mathrm{~g}$ of PEI was added to $500 \mathrm{~mL}$ of water and stirred for $12 \mathrm{~h}$ at $600 \mathrm{rpm}$. NaOHsolution: Solutions atpH10-10.5 of $\mathrm{NaOH}$ were also prepared and used for the preparation of both the PDDA solution and washing solutions. PDDA solution: $2.6 \mathrm{~g}$ of PDDA was added to $500 \mathrm{~mL}$ of $\mathrm{NaOH}$ solution $(\mathrm{pH} 10-10.5)$ and stirred for $12 \mathrm{~h}$ at $600 \mathrm{rpm}$.

\section{Procedure used for film deposition on solid substrates}

The glass slides and glass capillaries were cleaned with ethanol/water $(50 / 50 \mathrm{v} / \mathrm{v})$ in a sonicator bath for $15 \mathrm{~min}$. They were rinsed with water and dried under airflow. The clean substrates were first dipped in a solution of polycation (PEI or PDDA) for $20 \mathrm{~min}$ followed by a rinsing step (dipping 3 times of $2 \mathrm{~min}$ in 3 different containers) in $\mathrm{NaOH}$ solution $(\mathrm{pH}=10-10.5)$. Then, the glass supports were dipped in the suspension of $\mathrm{TiO}_{2}$ nanoparticles for $20 \mathrm{~min}$ followed by a rinsing step (dipping 3 times of $2 \mathrm{~min}$ in 3 different containers). Except for PEl, which was only used as first deposit in some cases, all the dipping $\left(\mathrm{PDDA}\right.$ or $\mathrm{TiO}_{2}$ ) and rinsing steps $(\mathrm{NaOH})$ were repeated to reach the desired film configuration (PEI or $\mathrm{PDDA}) /\left(\mathrm{TiO}_{2} / \mathrm{PDDA}\right)_{n-1}-\left(\mathrm{TiO}_{2}\right)_{1} / \mathrm{PDDAp}$ with $P=1,3,5,8,11$ and $P=0$ or 1 . The last stage of the procedure was to clean one side of the glass sides of the plates and the outside of the capillaries with an optical tissue soaked of ethanol.

\section{EPR measurements}

The coated capillaries were filled with $50 \mu \mathrm{L}$ nondeoxygenated TEMPOL solution in water at $200 \mu$ Mand sealed. A first spectrum was recorded to reach the initial EPR intensity (I0). For all measurements, the variations of the 10 values are less than $3 \%$. Then, successive illumination steps of $30 \mathrm{~s}$ were applied. Between each illumination step, one spectrum was recorded $(I=I(t))$. The experimental procedure is detailed in Figure S1c (Online Supplementary material). All the intensities values, proportional to the concentration of TEMPOL concentration $(/ \propto[T \bullet])$, were obtained after baseline correction and double integrations. EPR data were plotted as $1 / / 0$ vs. illumination time. Noteworthy, without the presence of paramagnetic probe, no EPR signal is detected.

\section{Results and discussions:}

The present proof of concept is twofold. At first, we demonstrated the controlled deposition of (polyelectrolyte/nano- $\left.\mathrm{TiO}_{2}\right)_{n}$ coatings on the inner surface of glass capillaries. Therefore, the amount of SC and polyelectrolyte can be tuned by the number $n$ of deposition steps (see Figure $\mathrm{S} 5$ and Table S2 (Online Supplementary material)). The full and comprehensive methodology for capillaries preparation is detailed in the Online Supplementary material. Second, following this rational approach, we investigated by EPR the photogeneration of reactive species induced by nano- $\mathrm{TiO}_{2}$-based films under UV excitation. An aqueous solution of TEMPOL $\left(\mathrm{T}^{*}\right)$ is used here as spin scavenger for reactive species. This EPR paramagnetic probe is known to react with: (i) low molecular weight radicals (such as $\mathrm{HO}^{\circ}, \mathrm{H}^{*}$ or $\left.\mathrm{HO}_{2}{ }^{\circ}\right)^{30}$ and (ii) electrons ${ }^{31}$, leading to diamagnetic compounds, i.e. EPR silent. Probing the decay of the TEMPOL EPR intensity provides a direct insight into the yield and kinetics of photogenerated reactive species. The deposition method described above has been achieved to coat capillaries with an increasing number of deposits $(P=1,3,5,8$ and 11). Figure 1 displays the evolution of TEMPOL EPR intensity $I(t)$ for an increasing number of $\mathrm{TiO}_{2}$ deposits as a function of illumination time $t$ and normalised with $\mathrm{I}_{0}=\mathrm{I}(\mathrm{t}=0)$. 


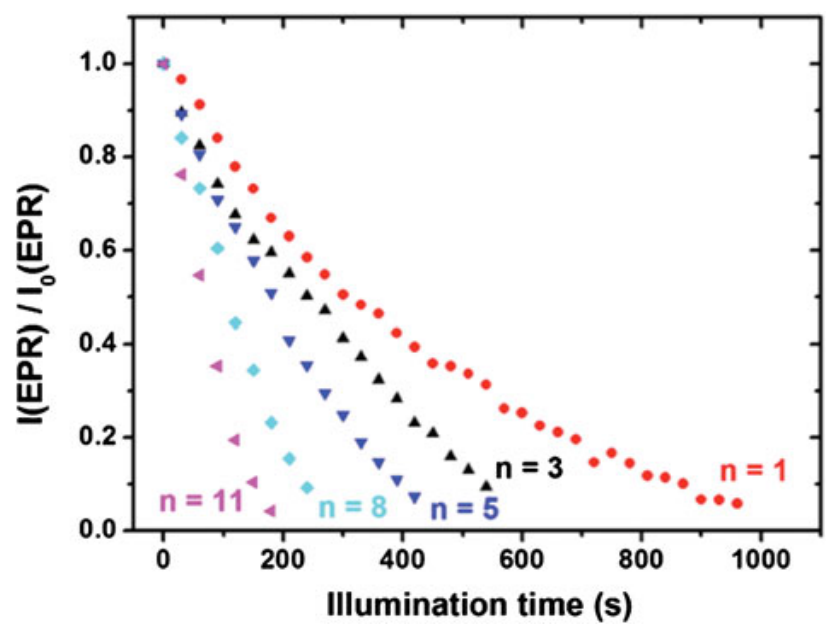

Figure 1. Evolution of the normalized TEMPOL EPR intensity $\left(I / I_{0}\right)$ as a function of the illumination time for different (polyelectrolyte/nano-TiO $\left.{ }_{2}\right)_{n}$ films: $n=1(\bullet), n=3(\Delta), n=5(\nabla), n=8(\bullet)$ and $n=11(\triangleleft)$.

It should be noted that for bare capillary, the TEMPOL EPR intensity remains constant for any illumination time ${ }^{32}$. In the presence of nano- $\mathrm{TiO}_{2}$, a decay of $\mathrm{I} / \mathrm{IO}$ is observed for all $n$ values, indicating the disappearance of the paramagnetic signal of TEMPOL induced by its reaction with photo-generated species produced by the nano- $\mathrm{TiO}_{2}$ within the films. Noteworthy, the behavior of two distinct capillaries prepared in the same conditions and with an identical $n$ value, presents very reproducible evolution (see Figures S6 and S9 (Online Supplementary material)). In addition, we also observed that other parameters such as presence/absence of the polyelectrolyte as last deposit (Figure S8 (Online Supplementary material)) or the nature of the polyelectrolyte first deposited (Figures S4 and S7 (Online Supplementary material)) do not influence the kinetic evolutions. A detectable variation of the intensity curve could only be seen when different $\mathrm{TiO}_{2}$ suspension batches were used to prepare the coatings (Figure S7 (Online Supplementary material)). Direct comparison of films with different $n$ values requires the use of the same nano- $\mathrm{TiO}_{2}$ stock suspension. Considering Figure 1 , the larger is $n$, the faster the kinetic. This correlates the quantity of photogenerated species and the amount of the involved nano- $\mathrm{TiO}_{2}$, i.e. the number of deposition steps. The present methodology involves accurate control of several parameters such as the volumes of film and solution, the geometry and the dimensions of the samples. Hence, through this EPR approach, it becomes possible to probe and to quantify the photo-generation characteristics of various $\mathrm{SC}$ thin films in contact with aqueous solution. Then, at this first step, the experimental data will be correlated to simple models. The first tested corresponds to the pure kinetic approach linked to the reaction where

$\mathrm{T}^{\bullet}+\mathrm{R}^{\bullet}=\mathrm{TR}^{\mathrm{n}}$

$\mathrm{dT} \% \mathrm{dt}=-\mathrm{K} \mathrm{T}^{\bullet} \mathrm{R}^{\bullet}$

with $T^{\bullet}=\left[T^{*}\right]$ and $R^{\bullet}=\left[R^{*}\right]$ corresponding to the concentration of TEMPOL and reactive species $\left(H^{\bullet}\right.$, $\left.\mathrm{OH}^{\circ}, \ldots\right)$, respectively, and $\mathrm{K}$ corresponds to the kinetic constant. A quadratic approach would agree with the reaction type ${ }^{33}$. Unfortunately, the boundary conditions, involving no photo-generated species prior to illumination (i.e. $R^{*}(t=0)=0$ ), preclude standard resolution of the differential equation (Equation 2). In this specific photo-generation process, the quasi steady-state approximation (QSSA) $)^{34}$ is valid, since the generated species have a very short lifetime either reacting with the spin scavenger and/or becoming by-products. Then, $\mathrm{dR} \% \mathrm{dt} \approx 0$ as no accumulation of radicals is possible. Thus, Equation (2) leads to the following first-order exponential decay:

$\mathrm{dT}^{\bullet} / \mathrm{dt}=-\mathrm{kT} \mathrm{T}^{\bullet}$ 
with $\mathrm{k}=\mathrm{KR} \cdot$ being an apparent kinetic constant and $K$ the real one. We applied this exponential fit to the experimental data and it does not match whatever $n$ (see Figure 2(A) for $P=5$ and Figure S12 (Online Supplementary material) for all $n$ values). A reason why a pure kinetic approach (Equation (3)) does not satisfy our data treatment could be the lack of consideration of diffusion phenomena. In our conditions, reactive species are photo-generated at the inner surface of the capillary. Considering the dimension of the capillary (radius of ca. $500 \mu \mathrm{m}$ ), the mass transport involved in the diffusion process may play a role and the kinetics may be consequently affected.

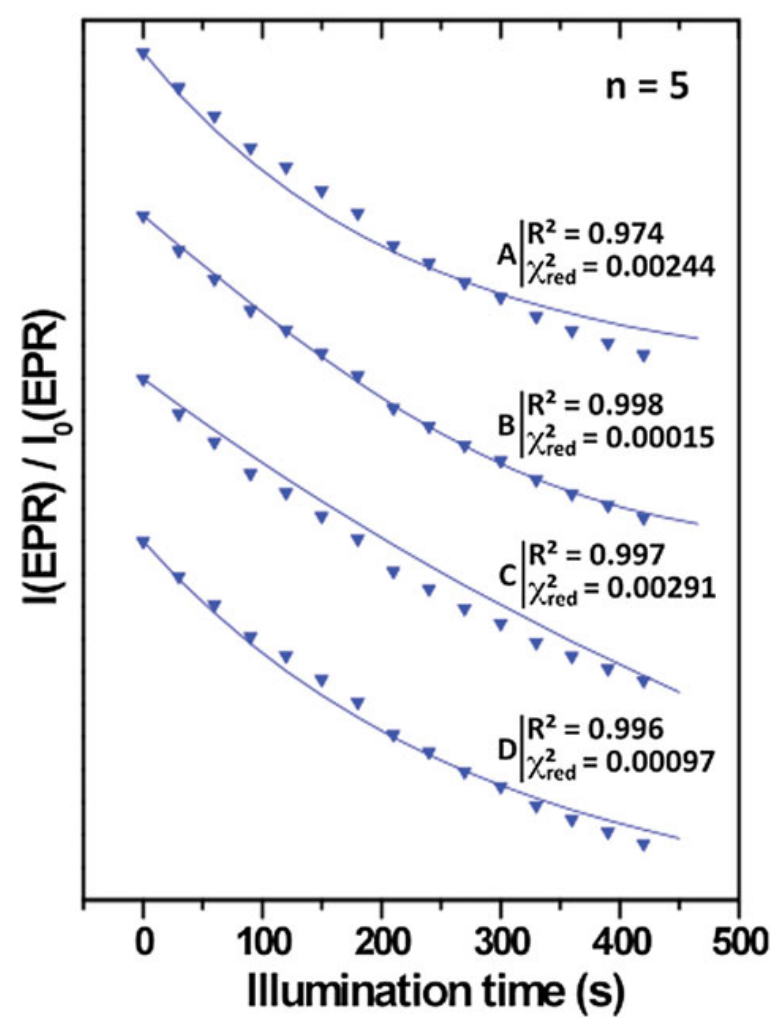

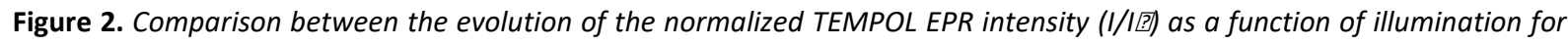
films with $P=5(\nabla)$ and the fitting attempts (solid line) based on an exponential model (A), the Gompertz model (B), a diffusion simulation with $k$ values from the Gompertz model (C) and a simulation with adjusted $k$ and $W(D)$. The reduced $\chi 2$ and the determination coefficient $R^{2}$ are given for each fit.

In cylindrical geometry, the Fick equation for solely a radial diffusion coupled with a chemical reaction is

$\partial T^{\bullet}(r, t) / \partial t=D\left[\partial^{2} T^{*}(r, t) / \partial r^{2}+(1 / r) \partial T^{*}(r, t) / \partial r\right]-k T^{*}(r, t)$

Although this type of equation admits an analytical solution (in the Laplace domain), it is usually seldom exact. Moreover, the experimental protocol involves illumination steps of $30 \mathrm{~s}$, which does not correspond to a continuous diffusion process. This situation can be more easily considered with a numerical approach. A solution of Equation (4) can be then obtained upon performing numerical simulation using partial differential equation (PDE) solver (such as FreeFem++) ${ }^{35}$.

As it can be observed from Figure 2(A), the experimental data do not follow an exponential evolution. In the context of the PDE solver, with the classical boundary condition ${ }^{35}$, i.e. Dirichlet (null concentration on the capillary/water interface) or Neumann condition (no gradient at the interface), pure exponential decays were obtained. A non-exponential evolution is observed when the boundary condition evolves with time. As the illumination steps were performed with the same duration and the same intensity, an identical amount of photogenerated electrons (defined as $W$ in this work) is 
produced for a given deposit. This value subtracted from the concentration of TEMPOL for each step will be the boundary condition. For simulation, the two factors $k$ and $W$ must be considered. Then, some compatible combinations of $k$ and $W$ have been assessed for $P=5$ (Figure 2(D)) as well as for all $n$ values (Figure S15 (Online Supplementary material)).

Accordance between the fits and the experimental data is clearly achieved although not being totally satisfying. Interestingly, this approach provides relevant information. Considering the QSSA hypothesis and the meaning of the $W$ parameter, the real kinetic constant $K$ should correspond to the ratio $k / W$ that it is quasi-constant for the set of $k, W$ values (Table S7). Hence, the hypothesis of the specific boundary condition for a pure diffusive behaviour related to the Fick PDE is validated and some comments can be made concerning the increasing agreement of the results at increasing $n$. If the best fits are obtained for low $n$ values $(P=1$ and 3$)$, a deviation is observed for higher $n$ values $(P=5,8$ and 11).

To confirm such hypothesis, i.e. all the experimental data following a unique behaviour, phenomenological approaches were considered. It turns out that a statistical model derived from the Gompertz mode ${ }^{36}$ offers a very good adequacy with respect to themeasured kinetics (see Figure 2(B) for $P=5$ and Figure S13 (Online Supplementarymaterial) for all $n$ values) irrespective to the $\mathrm{TiO}_{2}$ batch. This model corrects Equation (3) by a logarithmic factor such as

$\mathrm{dT} / \mathrm{dt}=-\mathrm{k} \mathrm{T}^{\bullet} \ln \left(\mathrm{Q} / \mathrm{T}^{\bullet}\right)$

with $Q$ being a constant related to the Gompertz model, whose solution of the differential equation is:

$\mathrm{T}^{\bullet} / \mathrm{T}_{0^{\bullet}}=\left(\mathrm{Q} / \mathrm{T}_{0}{ }^{\bullet}\right) \exp \left[-\ln \left(\mathrm{Q} / \mathrm{T}^{\bullet}\right) \exp (\mathrm{kt})\right]$

with the boundary condition: $T^{*}(t=0)=T^{*}$

An attempt has been performed with the $k$ values retrieved from the Gompertz fit (divided by 2.303) injected in the diffusion process. The results are presented in Figure 2(C) for $P=5$ and Figure S14 (Online Supplementary material) for all $n$ values. As it can be expected, there is no satisfactory agreement between the experimental data and the simulation (Figure 2(C)). While a quite poor matching is observed for small $n$ values $(P=1$ and 3$)$, the matching is slightly improved for larger $n$ values $(P=5,8$ and 11$)$. In contrast to the diffusion approach, the ratio $k / W a p p e a r s$ evolving when $k$ (Gompertz) are used (Table S6 (Online Supplemental material)). Obviously, this approach being phenomenological, the meaning of the constant is hardly definable. Yet, the experimental data clearly follow a well-defined behaviour.

Figure 3. Comparison of the apparent initial slope as a function of number $n$ of deposition steps: (i) linear fit $[\oplus]\left(T / T_{0}=1-\right.$

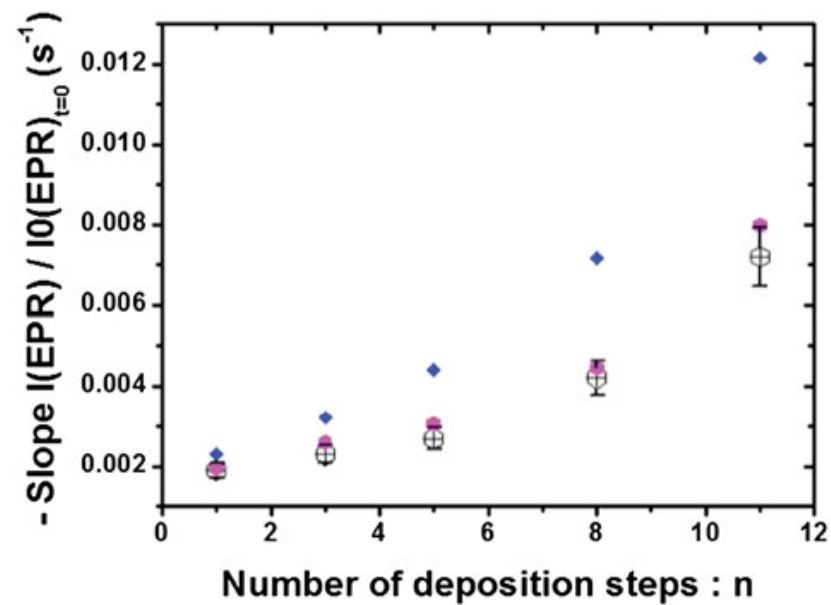

$k t)$; classical model of mono exponential decay $[\bullet]\left(T / T_{0}=\exp (-k t)\right.$ and model derived from the Gompertz approach [ ] (Equation (5)). 
Hence, the combination of the simulation results suggests that peculiar processes, deviating from a simple diffusion process coupled to chemical reaction and perfectly fitted by the Gompertz equation, must be considered. The phenomenological model brings valuable information related to a sigmoid evolution. This behaviour is either linked to specific properties of the studied object ${ }^{37}$ or the curve can be considered as a good approximation of the solution of the PDE and a more complex diffusion process would be then involved. These processes should have a growing importance with increasing $n$. As in our conditions, a film effect can be neglected: comparing the ratio of the volume ratio of the film to that of the solution (ca. $1 / \%$ or the highest $n$ value, see Online Supplemental Material), the related adsorption processes cannot be detected by EPR. Other hypotheses can be pointed out such as electrochemical reactions at the nano- $\mathrm{TiO}_{2}$ interface (oxidation and reduction of

$\mathrm{TEMPOL}^{31}$ ) and have also to be considered. This point is currently under extensive investigations. As presented in the introduction part, the possibility to work with solid state allows to better control physical parameters to answer such kind of questions. Finally, to compare the different data, the slope at $t=0$ is used. Figure 3 displays the comparison between fitted slope at $t=0$ (Figure S11 and Table S3 (Online Supplementary material)) and the slopes for the exponential and Gompertz evolutions. The agreement between the linear fit and the calculated Gompertz slope at $t=0$ is quite good in comparison to the exponential fit.

\section{Conclusion:}

In conclusion, we demonstrated as a proof of concept the potentiality to use EPR coupled to spin scavenging approach to probe and quantify data related to photogenerated species coming from controlled SC-based thin films prepared on the inner surface of submillimetre glass capillaries. We also showed that EPR results were reproducible independently of the first deposit (PEI or PDDA), the outermost deposit (PDDA or $\mathrm{TiO}_{2}$ ), the $\mathrm{TiO}_{2}$ suspension batch, and the storage conditions of the coated capillaries (dry or wet) (see Online Supplementary material). As expected, we observed that the amount of photogenerated species is correlated to the amount of SC incorporated in the films. The proposed approach allows confrontation with quantitativemodels. As first attempt, simple kinetic and mass transport models were considered. Both data analyses indicate that more complex phenomena must be considered. This interpretation is supported by the disappearance of the spin-scavenger probe that follows a sigmoid-like evolution in all measured conditions. The proposed well-controlled system can contribute to define the involved phenomena.

\section{Acknowledgments}

This work was supported by the Centre National de la Recherche Scientifique (CNRS), the Université de Strasbourg and the Institut Universitaire de France (IUF). We gratefully acknowledge Abdel Al Hamad for his assistance in EPR experiments and Marc Schmutz (ICS electronic microscopy platform) for the scanning electron microscopy pertinent advices. We acknowledge the French Ministry of Research and the Reseau NAtional de Rpe interDisciplinaire (RENARD, Fédération IRRPE CNRS \#3443).

\section{Funding}

This work was supported by the French Agence Nationale de la Recherche [SafeCoat project ANR-11SECU-0003].

\section{References}

[1] F.X.Xiao,M. Pagliaro,Y.J.Xu, and B.Liu, Chem. Soc. Rev. 45, 3088 (2016). doi:10.1039/C5CS00781J.

[2] X. Li, J. Yu, and M. Jaroniec, Chem. Soc. Rev. 45, 2603 (2016). doi:10.1039/C5CS00838G.

[3] M.H. Sun, S.Z. Huang, L.H. Chen, Y. Li, X.Y. Yang, Z.Y. Yuan, and B.L. Su, Chem. Soc. Rev. 45, 3479 (2016). doi:10.1039/C6CS00135A.

[4] A. Kubacka, M. Fernández-García, and G. Colón, Chem. Rev. 112, 1555 (2012). doi:10.1021/cr100454n. 
[5] B. Ohtani, Catalysts 6, 192 (2016). doi:10.3390/catal6120192.

[6] N.Mahmood, T. Tang, and Y. Hou, Adv. Energy Mater. 6, 1600374 (2016). doi:10.1002/aenm.201600374.

[7] M. Bonomo and D. Dini, Energies 9, 373 (2016). doi:10.3390/en9050373.

[8] M.L. Satuf, R.J. Brandi, A.E. Cassano, and O.M. Alfano, Ind. Eng. Chem. Res. 44, 6643 (2005). doi:10.1021/ie050365y.

[9] F.E. Gálvez, E. Kemppainen, H. Míguez, and J. Halme, J. Phys. Chem. C 116, 11426 (2012). doi:10.1021/jp2092708.

[10] A.L. Rogach, D.V. Talapin, E.V. Shevchenko, A. Kornowski, M. Haase, and H. Weller, Adv. Funct. Mater. 12, 653 (2002). doi:10.1002/1616- 3028(20021016)12:10<653::AID-ADFM653>3.0.CO;2-V.

[11] M.A. Henderson, Surf. Sci. Rep. 66, 185 (2011). doi:10.1016/j.surfrep.2011.01.001.

[12] R. Ramakrishnan, S. J.Devaki, A. Aashish, S. Thomas, M. Raama Varma, and N. KPP, J. Phys. Chem. C 120, 4199 (2016). doi:10.1021/acs.jpcc.5b10744.

[13] D. Martel, A. Guerra, P. Turek, J. Weiss, and B. Vileno, J. Colloid Interface Sci. 467, 300 (2016). doi:10.1016/j.jcis.2016.01.018.

[14] J.M. Meichtry, C. Colbeau-Justin, G. Custo, and M.I. Litter, Appl. Catal. B Environ. 144, 189 (2014). doi:10.1016/j.apcatb.2013.06.032.

[15] B. Liu, X. Zhao, J. Yu, A. Fujishima, and K. Nakata, Phys. Chem. Chem. Phys. 18, 31914 (2016). doi:10.1039/C6CP06320A.

[16] T.Wang, Z. Luo, C. Chengcheng, and J. Gong, Chem. Soc. Rev. 43, 7469 (2014). doi:10.1039/C3CS60370A.

[17] J. Ângelo, P. Magalhães, L. Andrade, and A. Mendes, Appl. Surf. Sci. 387, 183 (2016). doi:10.1016/j.apsusc.2016.06.101.

[18] J. Scheider, K. Nikitin, M. Wark, D.W. Bahnemann, and R. Marschall, Phys. Chem. Chem. Phys. 18, 10719 (2016). doi:10.1039/C5CP07115A.

[19] R.E. Rex, F.J. Knorr, and J.L. McHale, J. Phys. Chem. C 118, 16831 (2014). doi:10.1021/jp500273q.

[20] E.G. Panarelli, S. Livraghi, S. Maurelli, V. Polliotto, M. Chiesa, and E. Giamello, J. Photochem. Photobiol. A 322-323, 27 (2016). doi:10.1016/j.jphotochem.2016.02.015.

[21] F. Sannino, P. Pernice, C. Imparo, A. Aronne,G.D'Errico, L. Minieri, M. Perfetti, and D. Pirozzi, RSC Advances 5, 93831 (2015). doi:10.1039/C5RA21176J.

[22] D. Dvoranová, Z. Barbieriková, and V. Brezová, Molecules 19, 17279 (2014). doi:10.3390/ molecules191117279.

[23] P. Bertrand, La spectroscopie de Résonance Paramagnétique Electronique - Applications (EDP Science,Grenoble, 2014), pp. 49-79.

[24] D. Dontsova,V. Keller, N. Keller, P. Steffanut,O. Félix, and G. Decher, Macromol. Rapid Commun. 32, 1145 (2011). doi:10.1002/marc. 201100192.

[25] J. Rongé, J. Bets, S. Pattanaik , T. Bosserez, S. Borellini, S. Pulinthanathu Sree, G. Decher, and J.A. Martens, Catal. Today 246, 28 (2015). doi:10.1016/j.cattod.2014.07.051.

[26] E.R. Kleinfeld and G.S. Ferguson, Science 265, 370 (1994). doi:10.1126/science.265.5170.370.

[27] N.A. Kotov, I. Dekany, and J.H. Fendler, J. Phys. Chem. 99, 13065 (1995). doi:10.1021/j100035a005.

[28] G. Decher, Science 277, 1232 (1997). doi:10.1126/science.277.5330.1232.

[29] B. Ohtani, Y. Okugawa, S. Nishimoto, and T. Kagiya, J. Phys. Chem. 91, 3550 (1987). doi:10.1021/j100297a017.

[30] K. Matsumoto, K. Nagata, H. Yamamoto, K. Endo, K. Anzai, and I. Aoki, Magn. Reson. Med. 61, 1033 (2009). doi:10.1002/mrm.21958.

[31] Y. Kato, Y. Shimizu, L. Yijing, K. Unoura, H. Utsumi, and T. Ogata, Electrochim. Acta 40, 2799 (1995). doi:10.1016/0013-4686(95)00261-C.

[32] B. Vileno, P. Turek, J. Weiss, and D. Martel, CHEMPLUSCHEM 78, 1330 (2013). doi:10.1002/ cplu.201300201.

[33] D. Lavabre, V. Pimienta, G. Levy, and J.C. Micheau, J. Phys. Chem. 97, 5321 (1993). doi:10.1021/j100122a024.

[34] M. Bodenstein, Z. Phys. Chem. 85, 329 (1913). 
[35] F. Hecht, J. Numer. Math. 20, 251-265 (2012). doi:10.1515/jnum-2012-0013.

[36] C.P. Winsor, Proc. Natl. Acad. Sci. USA 18, 1 (1932). doi:10.1073/pnas.18.1.1.

[37] A. Khawam and D.R. Flanagan, J. Phys. Chem. B 110, 17315 (2006). doi:10.1021/jp062746a. 